Journal of Applied Pharmaceutical Science Vol. 7 (04), pp. 220-226, April, 2017

Available online at http://www.japsonline.com

DOI: $10.7324 / \mathrm{JAPS} .2017 .70433$

ISSN 2231-3354 (cc) EY-NC-SA

\title{
HAART and Hepatotoxicity
}

\author{
Devaraj Ezhilarasan ${ }^{1}$, Mohan Srilekha ${ }^{1}$, Ramanathan Raghu ${ }^{2}$ \\ ${ }^{1}$ Department of Pharmacology, Saveetha Dental College and Hospital, Chennai, Tamil Nadu, India. \\ ${ }^{2}$ Stem Cell Research Centre, Department of Surgical Gastroenterology and Liver Transplantation, Government Stanley Medical College and Hospital, \\ Chennai, India.
}

\section{ARTICLE INFO}

\section{Article history:}

Received on: 27/09/2016

Accepted on: 07/01/2017

Available online: 30/04/2017

\section{Key words:}

Zidovudine, hepatotoxicity, antiretroviral drugs, HIV.

\begin{abstract}
Antiretroviral (ARV) drugs are given in combination to treat the human immunodeficiency virus (HIV) infection and to prolong the life expectancy of the patient. The increase in the levels of hepatotoxicity due to the use of above drugs has been the concern till date. Lactic acidosis, hepatocytes fatty infiltration and oxidative stress are the commonly associated hepatotoxic effects with the administration of nucleoside reverse transcriptase inhibitors. Non-nucleooside reverse transcriptase inhibitors such as nevirapine and efavirenz inhibit bile acid transport causing cholestasis which in turn causes apoptosis to the hepatocytes. Furthermore, hepatitis $\mathrm{C}$ and $\mathrm{B}$ virus co-infection and Tuberculus bacilli in HIV infected patients remains a vital risk factor for the development of hepatotoxicity associated with highly active antiretroviral therapy (HAART). Overwhelming evidences clearly shows that the ARV drugs mediated hepatotoxicity has been attributed due to their mitochondrial interference. Although a low grade of hepatotoxicity resolves, high levels of toxicity leads to discontinuation of the therapy. Hence, careful observation is necessary especially during and after HAART to study the drug-induced liver diseases.
\end{abstract}

\section{INTRODUCTION}

Human immunodeficiency virus (HIV) related mortality and the risk of opportunistic infections has greatly decreased in recent years due to the use of highly active antiretroviral therapy (HAART) which employs the combination of two or more antiretroviral drugs for its treatment and are often referred as antiretroviral therapy (ART) (Egger et al., 2002). Though HAART have its potential to reduce progression of the disease in patients, they still have certain side effects which include liver toxicity, hematuria, decreased bone density, cardiovascular disease, gastrointestinal tract infection, hypersensitivity reaction, lactic acidosis, lipodystrophy, myopathy and Steven-Johns syndrome, etc. (Soriano et al., 2008). One of the major side effects caused by ART is

\footnotetext{
* Corresponding Author

Ezhilarasan Devaraj, Department of Pharmacology, Saveetha Dental College and Hospital, Chennai, Tamil Nadu,India. Email: ezhild@gmail.com
}

hepatotoxicity (Priyanka and Ezhilarasan, 2014). In fact, according to a recent report, AIDS- related illnesses account only around 50 $\%$ of the deaths, whereas HAART-induced liver injury has appears as a primary cause of death in HIV infected patients (Puri and Kumar, 2016). Hence, overwhelming research is being focused on HAART-related liver injury; especially in patients infected with both HIV and HCV (Bonacci et al., 2016; Casado et al., 2014) and remedial measure to protect the above drug-induced liver injury is the need of the hour.

The objective of this review is to discuss our knowledge in understanding the mechanisms of toxicity induced by antiretroviral (ARV) drugs in context to its hepatic physiology. The following section emphasizes on the importance of liver injury and its mechanisms, which results as a consequence of metabolism and/or due to direct cell toxicity by ARV drugs. The mechanism by which ARV drugs induced toxicity arises includes bile acid retention and apoptosis, mitochondrial dysfunction, endoplasmic reticulum (ER) stress and hepatocytes membrane damage by reactive oxygen species (ROS) (Figure1). 


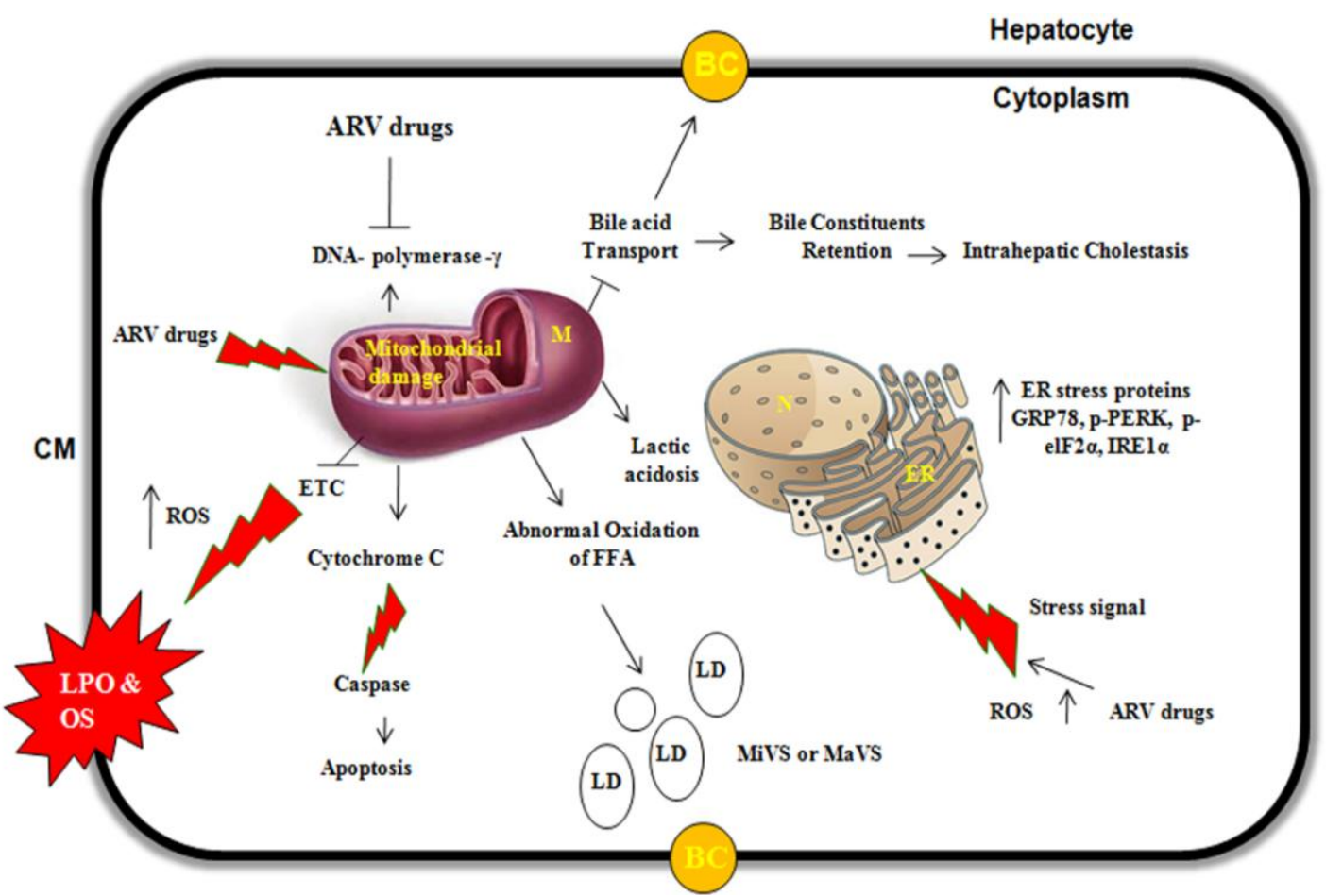

Fig. 1: mechanism of ARV drug induced hepatotoxicity. CM- hepatiocyte membrane; M- Mitochondria; N-Nucleus; ER-Endoplasmic reticulum; BC-bile canaliculi; LPO- lipid peroxidation; OS-Oxidative stress; LD- Lipoid droplets; MiVS- Microvesicular steatosis; MaVS- Macrovesicular steatosis; ETC- Electron Transfer; p-elF2 $\alpha$-eukaryotic translation initiation factor-2a; GRP78-glucose-regulated protein 78; p-PERK - protein kinase-like endoplasmic reticulum kinase; IREl $\alpha 0$ inositolrequiring and ER-to-nucleus signaling protein.

\section{Highly active antiretroviral therapy (HAART)}

The name HAART was introduced in the late 1990s to report the usefulness of combination drug therapies to treat HIV. The HAART regimen includes the combination of three or more antiretroviral drugs used effectively to suppress a wide variety of HIV infection. The main aim of employing HAART in HIV infected individuals is that if one drug is not able to suppress, the other drugs used in this combination will be more likely to suppress the HIV (Priyanka and Ezhilarasan, 2014). In context to liver, onset of severe liver injury initiating after HAART ranges from 2 to $18 \%$ and in USA, approximately 2000 cases of acute liver failure are being reported annually due to drug abuse which accounts for about $50 \%$ and $2-5 \%$ of these patients are being hospitalized with jaundice and approximately $10 \%$ with acute hepatitis (Núñez, 2010). Co-infection with hepatitis C virus (HCV) has also been documented as one of the foremost causes of chronic liver disease during HAART. Pre-existing hepatic fibrosis and accumulation of extracellular matrix during HAART is said to aggravate the risk of liver toxicity associated with ART (Wambani et al., 2015).

\section{HAART-induced hepatotoxicity}

Hepatotoxicity arises due to chemical / drug intake leading to severe liver damage. When some drugs taken in combination or even at therapeutic levels, overdose cause liver injury (Ezhilarasan and Karthikeyan, 2016; Ezhilarasan, 2016; Pandit et al., 2012). There are several risk factors which are said to play a pivotal role in the onset of hepatotoxicity in patients who are under therapy. The prophylaxis for HIV infections are influenced by many factors such as race, age, sex and hepatic drug reactions which are more common in females, and alcoholic persons. Liver disease patients with cirrhosis are at increased risk of developing drug toxicity due to drug formulations or genetic factors in patients under ARV therapy (Yang et al., 2016). Liver toxicity is one of the common manifestations in patients under ART and the role of HAART in HCV has been widely discussed. Antiretroviral therapy can initially increase hepatic inflammation, necrosis and accelerate chronic $\mathrm{HCV}$ progression. Therefore, many studies propose that $\mathrm{HIV} / \mathrm{HCV}$ co-infection may augment the risk of developing hepatotoxicity after ART and $\mathrm{HCV}$ act as an independent risk factor for the progression of hepatic disease in co-infected individuals during HAART. Hence, it has been advised that patients should be monitor for pre-existing liver diseases and most notably hepatitis B and C before initiating ART (Labarga et al., 2007).

Ironically, in a recent study, it has been reported that use of HAART therapy has shown the beneficial effect on the onset of liver fibrosis in HIV/HCV co-infected patients with advanced liver fibrosis (Chou et al., 2015). Despite the improved understanding of HAART mediated hepatotoxicity in HIV/HCV co-infected patients, the interaction remains controversial. To overcome the above scenario, patients can be routinely checked for basic liver function tests such as transaminases, bilirubin, urea and creatin levels after commencing HAART for the first 3 months. 
Table 1: Spectrum of antiretroviral drug induced hepatotoxicity.

\begin{tabular}{|c|c|c|}
\hline Drug & Spectrum of hepatotoxicity & References \\
\hline \multicolumn{3}{|c|}{ Nucleoside reverse transcriptase inhibitors (NRTIs) } \\
\hline Zidovudine & $\begin{array}{l}\text { Acute cholestatic hepatitis, inhibits DNA polymerase- } \gamma \text { in mitochondria, ER } \\
\text { stress, oxidative stress }\end{array}$ & $\begin{array}{l}\text { Raghu and Karthikeyan, 2016; Raghu et al., 2015; Banerjee et } \\
\text { al., 2013; Brinkman et al., 1998; Dubin and Braffman, } 1989\end{array}$ \\
\hline Stavudine & $\begin{array}{l}\text { Elevation of liver toxicity marker enzymes, lactic acidosis, inhibition of } \\
\text { mitochondrial oxidation of FFA - macrovesicular steatosis }\end{array}$ & $\begin{array}{l}\text { van Griensven et al., 2010; Gerschenson et al., 2001; Johri et } \\
\text { al., 2000; Lea and Faulds, } 1996\end{array}$ \\
\hline Lamivudine & $\begin{array}{l}\text { Elevation in serum ALT levels in patients co-infected with chronic HBV, } \\
\text { elevation of hepatotoxic and lipid marker enzymes in serum and plasma }\end{array}$ & Jesudas et al., 2016; Johri et al., 2000 \\
\hline \multicolumn{3}{|c|}{ Non- nucleoside reverse transcriptase inhibitors (NNRTIs) } \\
\hline Nevirapine & $\begin{array}{l}\text { Jaundice, hepatitis, hepatic necrosis, hepatic failure, elevation of liver } \\
\text { marker enzymes (AST/ALT) in chronic therapy }\end{array}$ & Ajulo et al., 2015; Bera et al., 2012; Hitti et al., 2004 \\
\hline Efavirenz & $\begin{array}{l}\text { Retention of bile constituents in hepatocytes - cholestasis - hepatocytes } \\
\text { apoptosis, inhibits bile acid transport in human/rat hepatocytes, high levels } \\
\text { of elevation of AST/ALT, hepatic steatotic changes, mitochondria and ER } \\
\text { stress }\end{array}$ & $\begin{array}{l}\text { Thamrongwonglert } \text { et al., 2016; Patil } \text { et al., 2015; Apostolova } \text { et } \\
\text { al., 2013; McRae } \text { et al., } 2006\end{array}$ \\
\hline \multicolumn{3}{|c|}{ Protease inhibitors (PIs) } \\
\hline Ritonavir & $\begin{array}{l}\text { Induction of hepatocytes apoptosis through caspase- } 3 \text { cascade system } \\
\text { Inhibits bile acid transport in human/rat hepatocytes } \\
\text { Increased risk of hepatotoxicity in HIV+TB infected patients with } \\
\text { rifampicin treatment }\end{array}$ & Mchunu et al., 2016; Kuang et al., 2014; Schmitt et al., 2009 \\
\hline Nelfinavir & Liver fibrosis, increased risk of severe hepatoxicity along with nevirapine & Mira et al., 2006 \\
\hline Saquinavir & Hindrance in bile acid transport inside the hepatocytes & McRae et al., 2006 \\
\hline Indinavir & Combination with Saquinavir can cause elevation of liver marker enzymes & Sulkowski et al., 2003 \\
\hline
\end{tabular}

In patients with the history of the pre-existing liver disease, investigation of liver function tests can be performed more frequently i.e., every 2 weeks after initiating the therapy. Clinically, it is in practice that once the liver marker enzymes of hepatotoxicity become stable; then the other less hepatotoxic drugs such as lamivudine and abacavir can be prescribe in patients who are at greater risk for developing hepatotoxicity (Kontorinis and Dieterich, 2003). In HIV-infected pregnant women using ARV therapy with an elevation of alanine aminotransferase (ALT) has been documented previously and is directly linked to liver toxicity (Huntington et al., 2014) (Table.1).

\section{Mechanism of ARV drug-induced hepatotoxicity}

Antiretroviral drugs are metabolized in the liver through cytochrome and its metabolizing enzymes which may even cause liver toxicity due to its polymorphisms (Bissell et al., 2001). Antiretroviral drugs inhibit the human mitochondrial DNA resulting in inhibition of normal mitochondrial replication which in turn decrease cellular respiratory chain thereby inhibits fatty acid $\beta$-oxidation pathway. There are previous reports suggesting ARV drugs-induced mitochondrial toxicity such as microvesicular hepatic steatosis, giant mitochondria and intrahepatic cholestasis. Studies have also concretely proved that interruption in electron transport chain results in the release of increased intracellular ROS leading to oxidative stress. These free radicals can cause lipid peroxidation of fatty acid present in the hepatocytes membrane consequently to release profibrogenic cytokines, fibrosis, and nuclear factor $\kappa \mathrm{B}$ to counteract the effect. Due to mitochondrial interaction cytochrome $\mathrm{c}$, an inter membrane protein is also released into cytosol which activates caspases pathway thereby triggers cellular apoptosis in hepatocytes (Kontorinis and Dieterich, 2003; Spengler et al., 2002).

\section{HEPATOTOXIC POTENTIALS OF NUCLEOSIDE REVERSE TRANSCRIPTASE INHIBITORS (NRTIS)}

\section{Zidovudine (AZT)}

Zidovudine, a nucleoside analogue is commonly used in combination with other ARV agents for the prophylaxis and treatment of the HIV infection (Martín Fernández et al., 1998). It was the first antiretroviral agent which received Food and Drug Administration (FDA) approval on March 19, 1987, for the treatment of HIV infection. In the same year, in October, Melamed and co-workers have reported the possible role of AZT-induced hepatotoxicity clinically (Melamed et al., 1987). Few studies have also reported acute cholestatic hepatitis after AZT administration (Raghu et al., 2015; Dubin and Braffman, 1989). Several experimental studies using rats and mice have also shown to develop oxidative stress leading to hepatotoxicity with AZT (Raghu et al., 2015). The AZT-induced hepatotoxicity could be suggested due to the impairment of mitochondrial DNA transcription and inhibition of DNA polymerase $\gamma$ in hepatocytes (Brinkman et al., 1998; Fromenty and Pessayre, 1995). The severity of AZT-induced hepatotoxicity is reported in experimental animals and such studies found that the mild and transient elevation of marker enzymes of hepatotoxicity to severe manifestations like inflammation, ER stress, fatty infiltration, lactic acidosis and hepatic failure leading to death. For this reasons, the clinical use of AZT is limited (Raghu et al., 2015; Banerjee et al., 2013).

\section{Stavudine (d4T)}

Stavudine is a thymidine analogue and is well-known ARV drug for its potential to induce hepatotoxicity and even acute liver failure. The $\mathrm{d} 4 \mathrm{~T}$ treatment can cause mild to transient 
elevation in liver marker enzymes due to hepatotoxicity which occurs in up to $50 \%$ of patients and lactic acidosis is often reported in these patients with high mortality rate (van Griensven et al., 2010; Lea and Faulds, 1996). In primates, chronic exposure of d4T has been reported to induce mitochondrial toxicity and there was a significant destruction of hepatocytes mitochondrial DNA found in the liver of d4T-exposed monkeys (Gerschenson, et al., 2001). Like other ARV drugs, d4T also interferes with mitochondrial catabolic beta-oxidation of free fatty acids causing the infiltration of lipid droplets in liver cells, manifesting as severe macrovesicular steatosis with hepatomegaly (Johri et al., 2000).

\section{Lamivudine (3-TC)}

Lamivudine is an L-enantiomer, substituted analogue of cytidine is said to be effective against both HIV and hepatitis B virus (HBV) infections. It was observed that lamivudine treatment elevated the liver aminotransferase levels in patients with chronic hepatitis B (Johri et al., 2000). These elevations appear due to a transient rise in patients with chronic HBV infection. Hence, patients should be carefully monitored after discontinuation of lamivudine therapy and if necessary treatment regimen should be started again promptly when decrease in clinical symptoms of hepatotoxicity (Núñez, 2010). Recent experimental studies have proved that chronic 3-TC administration consequently leads to an elevation in hepatotoxic and lipid marker enzymes in plasma of rats. The study also showed that ethanol intake could aggravate the 3-TC-induced hepatotoxicity in rats (Jesudas et al., 2016).

\section{HEPATOTOXIC POTENTIAL OF NON-NUCLEOSIDE REVERSE TRANSCRIPTASE INHIBITORS (NNRTIS)}

\section{Nevirapine}

Nevirapine is a non-nucleoside reverse transcriptase inhibitor commonly prescribed as a part of combination with other ARV drugs in the treatment of HIV/AIDS (Ajulo et al., 2015). It is commonly used ARV drug to treat HIV-1 infection in pregnant women to prevent gestational transmission. The nevirapineinduced hepatotoxicity is manifested as elevation of serum marker enzymes, bile duct obstruction and jaundice, hepatic necrosis, hepatitis and hepatic failure (Bera et al., 2012; Hitti et al., 2004). Clinical studies have reported that nevirapine is one of the wellcharacterized hepatotoxic ARV drug in spite of its efficacy and good tolerability with an occurrence of characteristic liver injury ranging from $10 \%$ to $18 \%$ in patients who are under therapy with nevirapine (Sanne et al., 2005). Clinically, symptomatic hepatitis is reported in $4 \%$ of patients taking nevirapine. The development of hepatotoxicity is reportedly high in female compared to male population. The liver hepatotoxic marker enzymes such as AST and ALT have shown to increase following chronic nevirapine therapy in children. Hence, it is advised that if the patients develop any clinical symptoms of hepatitis then the nevirapine treatment should be discontinued immediately. Generally, like other ARV drugs nevirapine also should be discontinued when elevation of serum aminotransferase levels occur associated with rashes (Ajulo et al., 2015). The data regarding the nevirapine-associated hepatitis and risk of developing hepatitis from subsequent treatment with other NNRTIs are scanty and hence further studies are warranted on theses lines. It is unfortunate that lack of clear guidelines till date regarding the discontinuation of nevirapine in HIV infected individuals who develop asymptomatic mild to moderate increases in hepatic aminotransferase levels are unavailable.

\section{Efavirenz}

Efavirenz is a non-nucleoside reverse transcriptase inhibitor which causes hepatotoxicity by blocking the bile acid transport. Bile formation is a vital function of the liver, and failure of bile formation and bile duct obstruction, retention of bile leads to cholestasis. The bile retention within the hepatocytes during cholestasis is associated with induction of apoptosis in hepatocytes (Patel et al., 1998). Previous studies in human and rat hepatocytes using efavirenz is reported to inhibit bile acid transport (McRae et al., 2006). Efavirenz, when administered in combination with Emtricitabine/Tenofovir (one of the first-line agents for the treatment of HIV), causes hepatotoxicity characterized by high levels of hepatic aminotransferases (Patil et al., 2015). Rilpivirine, another NNRTI has shown to be more advantageous when compared to efavirenz. In a recent study, it has been confirmed that rilpivirine has better lipid profiles compared to efavirenz when these drugs are administered in HIV patients and it is also shown that efavirenz attributed to inducing abnormal lipid changes (Thamrongwonglert et al., 2016).

The mechanisms related to hepatotoxicity induced by efavirenz are not clear, nevertheless, a recent study has reported that the mitochondrial toxicity of this drug is accompanied by an induction of ER stress in human hepatocytes (Apostolova et al., 2013). In light of the above literature, a recent study has confirmed the role of mitochondrial and ER stress to be the key factor for efavirenz-induced hepatotoxicity (Polo et al., 2015). However, as we seen earlier the mechanism of efavirenz- induced hepatotoxicity is not well characterized till date but it is considered to occur less frequently than with nevirapine (Sonderup et al., 2016).

\section{PROTEASE INHIBITORS (PIs)}

HIV protease inhibitors are the type of ART which inhibits the protein synthesis thereby inhibits viral replication. There are around nine HIV-PIs approved by FDA such as saquinavir, nelfinavir, lopinavir, amprenavir, atazanavir, darunavir, tipranavir, indinavir and most of these drugs are structural homologs to ritonavir (Wlodawer and Vondrasek, 1998).

\section{Ritonavir}

Ritonavir is the most widely and frequently used PI causing hepatotoxicity. This drug is mostly used in combination with other NRTIs or NNRTIs. Ritonavir is shown to inhibit hepatocyte proliferation and apoptosis via caspase-3 activation. 
The mechanism of ritonavir-induced hepatotoxicity has been attributed due to induction of apoptosis of hepatocytes via the caspase-cascade system (Kuang et al., 2014). In previous studies, ritonavir is reported to inhibit bile acid transport in human and rat hepatocytes (McRae et al., 2006). HIV-infected individuals are often co-infected by many bacterial infections, including Tuberculus bacilli. These patients are treated with anti-tubercular drugs daily, for several months, depending upon the severity of infection, in addition to their routinely administered regimens of anti-retroviral drugs (Mchunu et al., 2016; Raghu and Karthikeyan, 2016). HIV-infected individuals are often co-infected by many bacterial infections, including Tuberculus bacilli. These patients are treated with anti-tubercular drugs along with ARV drugs. Thus co-administration of PIs such as saquinavir/ritonavir (1000/100 mg twice daily) and rifampin (600 mg once daily) in HIV-negative volunteers showed a speedy and significant increase in liver enzymes. Hence, it has been suggested that the combination and co-administration of saquinavir/ritonavir and rifampicin show contraindication in HIV patients (Schmitt et al., 2009).

\section{Nelfinavir}

Nelfinavir is widely used PIs as a first-line in HIVinfected patients. The nelfinavir-induced hepatotoxicity was reported to less when compared to NNRTIs and other PIs (Sulkowski et al., 2004). Interestingly, the incidence of liver toxicity of nelfinavir-containing HAART regimens has been found low among HIV/HCV-coinfected patients with hepatic fibrosis. However, it is reported that nelfinavir administered with nevirapine, showed an increased risk of developing severe hepatotoxicity (Mira et al., 2006).

\section{Saquinavir and Indinavir}

Saquinavir is the first PI approved by FDA and its toxicity is reported on a longer usage of ARV drugs. Saquinavir in combination with ritonavir causes rapid onset of acute hepatic injury (Wambani et al., 2015). Saquinavir is reported to inhibit bile acid transport leading to retention of bile which causes apoptosis of human and rat hepatocytes (McRae et al., 2006). The saquinavir and indinavir-induced liver toxicity ranges from mild transient elevation to severe causing hepatotoxicity. The injury is self-limited, but it can also cause acute liver failure and death (Sulkowski, 2003).

\section{Management and Prevention of ARV-induced hepatotoxicity}

In general, most of the drug-induced liver injury is difficult to predict and hence it has been advised that the clinician must be aware of the patient's predisposing risk factors for ARV drugs induced liver injury, which will help them in guiding and monitoring the patient (Soriano et al., 2008). Regularly monitoring the levels of transaminases (AST and ALT) should be made mandatory before commencement and during ARV therapy. The less hepatotoxic ARV drugs such as lamivudine and abacavir can be prescribed to patients who are under high risk of developing liver toxicity (Martinez et al, 2001). Once the hepatotoxicity is confirmed in patients undergoing ARV therapy, the treatment can be discontinued for a short period so that the liver can recover from its injury as it has a natural regenerating capacity. Though liver can regenerate, its recovery depends on the dosage and the severity of the toxicity. As of now, the only effective treatment till date is discontinuation of the drug (Sulkowski et al., 2004). Hence, as a remedial measure, the dosage of antiretroviral drugs can be prescribed to patients in accordance with Department of Health and Human Services guidelines to overcome the above issue (Soriano, 2014).

\section{CONCLUSION}

Undoubtedly, hepatotoxicity is one of the most serious complications in patients who is undergoing ARV therapy which further increases when they are co-infected with hepatitis virus. Hepatic steatosis and lactic acidosis are commonly observed in patients administered with antiretroviral nucleoside analogs, such as AZT, didanosine, zalcitabine, Combivir (AZT+3-TC) and 3-TC. While ARV durgs such as ritonavir, efavirenz and nevirapine are commonly reported for their hindrance in bile acid transport inside the liver.

These results clearly confirm that the ARV drugs induce hepatotoxicity due to its mitochondrial interference. Moreover, the corresponding triphosphate, produced by the virus also inhibits host DNA polymerase consequent to compensatory glycolysis and lactic acidosis leading to hepatotoxicity. Though the usage of ARV drugs during pregnancy is considered not to be safe, the HAART has significantly contributed to the reduction of mortality and morbidity in HIV-infected patients. To overcome the above challenge, the patients can be regularly monitored for the levels of toxicity and HAART regimen should be discontinued if the patients manifest hepatotoxicity due to the use of the above drugs. Pharmacovigilance of ARV drugs and HAART regimen-induced adverse drug reactions especially in liver is the need of the hour.

\section{Financial support and sponsorship: Nil.}

Conflict of Interests: There are no conflicts of interest.

\section{REFERENCES}

Ajulo MO, Omole MK, Moody JO, Dixon-Umo OT, Salami OL. Liver aminotransferases in under-five HIV-positive children on HAART. Afr J Med Med Sci 2015; 44:197-204.

Apostolova N, Gomez-Sucerquia LJ, Alegre F, Funes HA, Victor VM, Barrachina MD, Blas-Garcia A, Esplugues JV. ER stress in human hepatic cells treated with Efavirenz: mitochondria again. J Hepatol 2013; 59:780-789.

Banerjee A, Abdelmegeed MA, Jang S, Song BJ. Zidovudine (AZT) and hepatic lipid accumulation: implication of inflammation, oxidative and endoplasmic reticulum stress mediators. PLoS One 2013; 8 : e76850.

Bera E, Naidoo D, Williams M. Maternal deaths following nevirapine-based antiretroviral therapy. South Africa J HIV Med 2012; 13:196-197.

Bissell D, Gores G, Laskin D, Hoofnagle JH. Drug-induced liver injury: mechanisms and test systems. Hepatology 2001; 33:1009-13. 
Bonacci M, Lens S, Mariño Z, Forns X. Challenges in Special Populations: HIV/HCV Coinfection, Liver Transplantation and Patients with End-Stage Renal Disease. Dig Dis 2016; 34:317-326.

Brinkman K, ter Hofstede HJ, Burger DM, Smeitink JA, Koopmans PP. Adverse effects of reverse transcriptase inhibitors: mitochondrial toxicity as common pathway. AIDS 1998; 12:1735-1744.

Casado JL, Mena A, Bañón S, Moreno A, Castro A, Perez-Elías MJ, Pedreira J, Moreno S. Efficacy and safety of etravirine-containing regimens in a large cohort of $\mathrm{HIV} / \mathrm{HCV}$ coinfected patients according to liver fibrosis. J Int AIDS Soc 2014; 17:19574.

Chou CC, Tsai HC, Wu KS, Sy CL, Chen JK, Chen YS, Lee SS. Highly active antiretroviral therapy-related hepatotoxicity in human immunodeficiency virus and hepatitis $\mathrm{C}$ virus co-infected patients with advanced liver fibrosis in Taiwan. J Microbiol Immunol Infect 2016; 49:546-553.

Dubin G, Braffman MN. Zidovudine-induced hepatotoxicity. Ann Intern Med 1989; 110:85-86.

Egger M, May M, Chêne G, Phillips AN, Ledergerber B, Dabis F, Costagliola D, D'Arminio Monforte A, de Wolf F, Reiss P, Lundgren JD, Justice AC, Staszewski S, Leport C, Hogg RS, Sabin CA, Gill MJ, Salzberger B, Sterne JA; ART Cohort Collaboration ART Cohort Collaboration. Prognosis of HIV-1-infected patients starting highly active antiretroviral therapy: a collaborative analysis of prospective studies. Lancet 2002; 360:119-129.

Ezhilarasan D, Karthikeyan S. Silibinin alleviates $N$ nitrosodimethylamine-induced glutathione dysregulation and hepatotoxicity in rats. Chin J Nat Med 2016; 14:40-47.

Ezhilarasan D. Hepatoprotective properties of Dandelion: recent update. J Appl Pharm Sci 2016; 6:202-205.

Fromenty B, Pessayre D. Inhibition of mitochondrial betaoxidation as a mechanism of hepatotoxicity. Pharmacol Ther 1995; 67:101-154.

Gerschenson M, Nguyen VT, St Claire MC, Harbaugh SW, Harbaugh JW, Proia LA, Poirier MC. Chronic stavudine exposure induces hepatic mitochondrial toxicity in adult Erythrocebus patas monkeys. J Hum Virol 2001; 4:335-342.

Hitti J, Frenkel LM, Stek AM, Nachman SA, Baker D, Gonzalez-Garcia A, Provisor A, Thorpe EM, Paul ME, Foca M, Gandia J, Huang S, Wei LJ, Stevens LM, Watts DH, McNamara J; PACTG 1022 Study Team. PACTG 1022 Study Team. Maternal toxicity with continuous nevirapine in pregnancy: results from PACTG 1022. J Acquir Immune Defic Syndr 2004; 36:772-776.

Huntington S, Thorne C, Anderson J, Newell ML, Taylor G, Pillay D, Hill T, Tookey P, Sabin C. Does pregnancy increase the risk of ART-induced hepatotoxicity among HIV-positive women? J Int AIDS Soc $2014 ; 17: 19486$.

Jesudas B, Raghu R, Bhavani G, Ezhilarasan D, Karthikeyan S. Ethanol enhances lamivudine-induced liver toxicity: investigation on hepatoprotective properties of silibinin-phosphotidyl choline complex in rats. Biomedicine 2016; 36:128-137.

Johri S, Alkhuja S, Siviglia G, Soni A. Steatosis-lactic acidosis syndrome associated with stavudine and lamivudine therapy. AIDS 2000; 14:1286-1287.

Kontorinis N, Dieterich D. Hepatotoxicity of antiretroviral therapy. AIDS Rev 2003; 5:36-43.

Kuang CC, Wang Y, Hu PC, Gao FF, Bu L, Wen XM, Xiang QM, Song H, Li Q, Wei L, Li K. Ritonavir-induced hepatotoxicity and ultrastructural changes of hepatocytes. Ultrastruct Pathol 2014; 38:329334.

Labarga P, Soriano V, Vispo ME, Pinilla J, Martin-Carbonero L, Castellares C, Casado R, Maida I, Garcia-Gasco P, Barreiro P. Hepatotoxicity of antiretroviral drugs is reduced after successful treatment of chronic hepatitis C in HIV-infected patients. J Infect Dis 2007; 196:670-676.

Lea AP, Faulds D. Stavudine: a review of its pharmacodynamic and pharmacokinetic properties and clinical potential in HIV infection. Drugs 1996; 51:846-864.
Martín Fernández J, Rubio García R, Pulido Ortega F. Past, present and future of zidovudine, the first antiretroviral drug. An Med Interna 1998; 15:163-170.

Martínez E, Blanco JL, Arnaiz JA, Pérez-Cuevas JB, Mocroft A, Cruceta A, Marcos MA, Milinkovic A, García-Viejo MA, Mallolas J, Carné X, Phillips A, Gatell JM. Hepatotoxicity in HIV-1-infected patients receiving nevirapine-containing antiretroviral therapy. AIDS 2001; 15:1261-1268.

Mchunu G, van Griensven J, Hinderaker SG, Kizito W, Sikhondze W, Manzi M, Dlamini T, Harries AD. High mortality in tuberculosis patients despite HIV interventions in Swaziland. Public Health Action 2016; 6:105-110.

McRae MP, Lowe CM, Tian X, Bourdet DL, Ho RH, Leake BF, Kim RB, Brouwer KL, Kashuba AD. Ritonavir, saquinavir, and efavirenz, but not nevirapine, inhibit bile acid transport in human and rat hepatocytes. J Pharmacol Exp Ther 2006; 318:10681075 .

Melamed AJ, Muller RJ, Gold JW, Campbell SW, Kleinberg ML, Armstrong D. Possible zidovudine-induced hepatotoxicity. JAMA 1987; 258:2063.

Mira JA, Macías J, Girón-González JA, Merino D, GonzálezSerrano M, Jiménez-Mejías ME, Caballero-Granado FJ, Torre-Cisneros J, Terrón A, Becker MI, Gómez-Mateos J, Arizcorreta-Yarza A, Pineda JA; Grupo Andaluz Para el Estudio de las Enfermedades Infecciosas (GAEI). Incidence of and risk factors for severe hepatotoxicity of nelfinavircontaining regimens among HIV-infected patients with chronic hepatitis C. J Antimicrob Chemother 2006; 58:140-146.

Núñez M. Clinical syndromes and consequences of antiretroviral-related hepatotoxicity. Hepatology 2010; 52:1143-1155.

Pandit A, Sachdeva T, Bafna P. Drug-Induced Hepatotoxicity: A Review. J Appl Pharm Sci 2012; 2;233-243.

Patel T, Roberts LR, Jones BA, Gores GJ. Dysregulation of apoptosis as a mechanism of liver disease: An overview. Semin. Liver Dis 1998; 18:105-114

Patil R, Ona MA, Papafragkakis H, Carey J, Moshenyat Y, Alhaddad A, Anand S. Acute Liver Toxicity due to Efavirenz/Emtricitabine/Tenofovir. Case Reports Hepatol 2015; 2015:280353.

Polo M, Alegre F, Funes HA, Blas-Garcia A, Victor VM, Esplugues JV, Apostolova N. Mitochondrial (dys)function - a factor underlying the variability of efavirenz-induced hepatotoxicity? $\mathrm{Br} \mathrm{J}$ Pharmacol 2015; 172:1713-1727.

Priyanka S, Ezhilarasan D. HIV Infections and Highly Active Anti-Retroviral Therapy. J Pharm Sci Res 2015; 7:557-559.

Puri P, Kumar S. Liver involvement in human immunodeficiency virus infection. Indian J Gastroenterol 2016; 35(4):260273.

Raghu R, Jesudas B, Bhavani G, Ezhilarasan D, Karthikeyan S. Silibinin mitigates zidovudine-induced hepatocellular degenerative changes, oxidative stress and hyperlipidaemia in rats. Hum Exp Toxicol 2015; 34:1031-1042.

Raghu R, Karthikeyan S. Zidovudine and isoniazid induced liver toxicity and oxidative stress: Evaluation of mitigating properties of silibinin. Environ Toxicol Pharmacol 2016; 46: 217-226.

Sanne I, Mommeja-Marin H, Hinkle J, Bartlett JA, Lederman MM, Maartens G, Wakeford C, Shaw A, Quinn J, Gish RG, Rousseau F. Severe hepatotoxicity associated with nevirapine use in HIV-infected subjects. J Infect Dis 2005; 191:825-829.

Schmitt C, Riek M, Winters K, Schutz M, Grange S. Unexpected Hepatotoxicity of Rifampin and Saquinavir/Ritonavir in Healthy Male Volunteers. Arch Drug Inf 2009; 2:8-16.

Sonderup MW, Maughan D, Gogela N, Setshedi M, Wainwright $\mathrm{H}$, Meintjes G, Spearman W. Identification of a novel and severe pattern of efavirenz drug-induced liver injury in South Africa. AIDS 2016; 30:1483-1485.

Soriano V, Puoti M, Garcia-Gascó P, Rockstroh JK, Benhamou $\mathrm{Y}$, Barreiro P, McGovern B. Antiretroviral drugs and liver injury. AIDS $2008 ; 22: 1-13$. 
Soriano V. Update of the DHHS antiretroviral treatment guidelines. AIDS Rev 2014; 16:117-118.

Spengler U, Lichterfeld M, Rockstroh JK. Antiretroviral drug toxicity -- a challenge for the hepatologist? J Hepatol 2002; 36:283-294.

Sulkowski MS, Mehta SH, Chaisson RE, Thomas DL, Moore RD. Hepatotoxicity associated with protease inhibitor-based antiretroviral regimens with or without concurrent ritonavir. AIDS 2004; 18:2277-2284.

Sulkowski MS. Hepatotoxicity associated with antiretroviral therapy containing HIV-protease inhibitors. Semin Liver Dis 2003; 23:183-194.

Thamrongwonglert $\mathrm{P}$, Chetchotisakd $\mathrm{P}$, Anunnatsiri S, Mootsikapun P. Improvement of lipid profiles when switching from efavirenz to rilpivirine in HIV-infected patients with dyslipidemia. HIV Clin Trials 2016; 17:12-16.

van Griensven J, Zachariah R, Rasschaert F, Mugabo J, Atté EF, Reid T. Stavudine-and nevirapine-related drug toxicity while on generic fixed-dose antiretroviral treatment: incidence, timing and risk factors in a three-year cohort in Kigali, Rwanda. Trans R Soc Trop Med Hyg 2010; 104:148-153.
Wambani JR, Ogola PE, Arika WM, Rachuonyo HO, Burugu MW. Global Situation and Trends of HIV, Influenza and Marburg Viruses: An Epidemiological Perspective. J Emerg Infect Dis 2016; 1:105.

Wlodawer A, Vondrasek J. Inhibitors of HIV-1 protease: a major success of structure-assisted drug design. Annu Rev Biophys Biomol Struct 1998; 27:249-284.

Yang Z, Huang Z, Dong Z, Li J, Zhang S, Wu N, Jin M. Risk factors for HIV diagnosis among men who have sex with men: Results of a case-control study in one sample of eastern China. AIDS Res Hum Retroviruses 2016.

\section{How to cite this article:}

Ezhilarasan D, Srilekha S, Raghu R. HAART and Hepatotoxicity. J App Pharm Sci, 2017; 7 (04): 220-226. 